\title{
Therapy response assessment with quantitative PET: evaluation of a shortened acquisition protocol with dynamic PET/CT
}

\author{
C Pfannenberg ${ }^{*}$, SC Schüle, C Brendle, J Schwenck, K Nikolaou, C La Fougère, J Kupferschläger \\ From International Cancer Imaging Society (ICIS) 14th Annual Teaching Course \\ Heidelberg, Germany. 9-11 October 2014
}

\section{Purpose}

The results of SUV quantification for prediction of histopathological response in patients with oesophageal carcinoma show high variations with different accuracy. However, the routine use of a full dynamic PET is limited because of long acquisition times. We tested a shortened acquisition protocol for quantitative PET to overcome that limitation.

\section{Material and methods}

13 patients with histopathologically proven oesophageal adenocarcinoma underwent a combined dynamic and static ${ }^{18} \mathrm{~F}$-FDG PET/CT including CT tumour perfusion (Siemens, Biograph mCT). Dynamic PET (listmode) was acquired for 60 min resulting in 38 frames from 10 to $600 \mathrm{sec}$ duration for the full dynamic dataset and 2 frames each with $600 \mathrm{sec}$ duration (20-30 min and 50-60 min p.i.) for dual time point PET (DTP). We evaluated the metabolic rate Ki using different models: 2-compartment irreversible model (Fit), Patlak plot and DTP (van den Hoff et al). The CT tumour perfusion protocol included the parameters blood flow, blood volume and permeability.

\section{Results}

The metabolic rate Ki could be reliably reproduced independent of the analytical model; we observed only slight variations of $\mathrm{Ki}$ with respect to the analytical model: $-4,9 \%$ (Patlak vs.Fit), $-10 \%$ (DTP vs.Fit) and $-5,1 \%$ (DTP vs. Patlak). A linear regression revealed a strong correlation of the Ki values: $R^{2}=0,996$ (Patlak vs. Fit), $R^{2}=0,968$ (DTP vs.Fit) and $R^{2}=0,985$ (Patlak vs. DTP).

* Correspondence: christina.pfannenberg@med.uni-tuebingen.de Department of Radiology, Eberhard-Karls-University Tuebingen, Germany

\section{Conclusion}

The shortened dynamic acquisition protocol of DTP-PET is a reliable method for the determination of the metabolic rate $\mathrm{Ki}$ and can substitute a full dynamic scan for improved quantitative assessment of therapy response.

Published: 9 October 2014

doi:10.1186/1470-7330-14-S1-S1

Cite this article as: Pfannenberg et al:: Therapy response assessment with quantitative PET: evaluation of a shortened acquisition protocol with dynamic PET/CT. Cancer Imaging 2014 14(Suppl 1):S1.
Submit your next manuscript to BioMed Central and take full advantage of:

- Convenient online submission

- Thorough peer review

- No space constraints or color figure charges

- Immediate publication on acceptance

- Inclusion in PubMed, CAS, Scopus and Google Scholar

- Research which is freely available for redistribution
() Biomed Central 